\title{
Mind Operational Semantics and Brain Operational Architectonics: A Putative Correspondence
}

\author{
Giulio Benedetti*,1 ${ }^{*}$, Giorgio Marchetti ${ }^{1,2}$, Alexander A. Fingelkurts ${ }^{3}$ and Andrew A. Fingelkurts*,3 \\ ${ }^{I}$ Mind, Consciousness, and Language research net, Italy; ${ }^{2}$ University of Urbino, Urbino PU, Italy; ${ }^{3}$ BM-Science - Brain \\ and Mind Technologies Research Centre, P.O. Box 77, FI-02601, Espoo, Finland
}

\begin{abstract}
Despite allowing for the unprecedented visualization of brain functional activity, modern neurobiological techniques have not yet been able to provide satisfactory answers to important questions about the relationship between brain and mind. The aim of this paper is to show how two different but complementary approaches, Mind Operational Semantics (OS) and Brain Operational Architectonics (OA), can help bridge the gap between a specific kind of mental activitythe higher-order reflective thought or linguistic thought-and brain. The fundamental notion that allows the two different approaches to be jointly used under a common framework is that of operation. According to OS, which is based on introspection and linguistic data, the meanings of words can be analyzed in terms of elemental mental operations (EOMC), amongst which those of attention play a key role. Linguistic thought is made possible by special kinds of elements, which OS calls "correlators", which have the function of tying together the other elements of thought, which OS calls "correlata" (a "correlational network" that is, a sentence, is so formed). Therefore, OS conceives of linguistic thought as a hierarchy of operations of increasing complexity. Likewise, according to OA, which is based on the joint analysis of cognitive and electromagnetic data (EEG and MEG), every conscious phenomenon is brought to existence by the joint operations of many functional and transient neuronal assemblies in the brain. According to OA, the functioning of the brain is always operational (made up of operations), and its structure is characterized by a hierarchy of operations of increasing complexity: single neurons, single assemblies of neurons, synchronized neuronal assemblies or Operational Modules (OM), integrated or complex OMs. The authors put forward the hypothesis that the whole level of OS's description (EOMC, correlators, and correlational networks) corresponds to the level of OMs (or set of them) of different complexity within OA's theory: EOMC could correspond to simple OMs, correlators to complex OMs and the correlational network to a set of simple and complex OMs. Finally, a set of experiments is proposed to verify the putative correspondence between OS and $\mathrm{OA}$ and prove the existence of an integrated continuum between brain and mind.
\end{abstract}

Keywords: Mental categories, consciousness, linguistic thought, language, attention, mental operations, EEG, functional synchrony, connectivity, metastability.

\section{INTRODUCTION}

Despite allowing for the unprecedented visualization of brain functional activity, modern neurobiological techniques have not yet been able to provide satisfactory answers to important questions about the relationship between brain and mind. Precisely, in the specific field of the studies of the relationship between brain and reflective consciousness [1], where the natural human language plays an important role, there is still no common consensus among neuroscientists even about which cortical areas (or neural processes) are involved in the processing of, and phenomenally constituting, the meanings of words. For example, on the basis of both lesion and positron emission tomography (PET) data, Tranel and Damasio [2] emphasize the role of the left

*Address correspondence to these authors at the Mind, Consciousness, and Language research net, Italy, E-mails: benedetti.giulio@tiscali.it; info@mind-consciousness-language.com

BM-Science - Brain \& Mind Technologies Research Centre, Finland;

Tel: 39 050564474; E-mail: fingelkurts@bm-science.com inferior and middle temporal gyri, while based on PET and electroencephalographic (EEG) data, Posner and Di Girolamo [3] argue for semantic processes in left inferior frontal areas. At the same time, based on magnetoencephalographic (MEG) evidence, Salmelin, Helenius, and Kuukka [4] claim that the left superior temporal lobe is relevant for word semantics; and Skrandies [5] reports EEG studies highlighting the importance of the occipital lobes in distinguishing word meanings, whilst Pulvermüller [6] stresses the importance of primary motor, premotor and prefrontal areas for wordmeaning processing.

As Pulvermüller has properly observed referring to the difficulty of modern neurobiological techniques to localize the cortical areas involved in semantic processing, probably this shortcoming of cognitive neuroscience is partly due to the lack of an adequate theoretical apparatus: "In spite of the undeniable progress made possible by empirical results obtained with newly introduced techniques, it is likely that theoretical advances are necessary as well" (Ref. [7], pp. 47).

In our opinion, in order to identify the brain structures and mechanisms responsible for the production of higherorder mental phenomena such as thought and semantic proc- 
essing, a theoretical framework proposing what to look for and at which level to do it is the necessary guide. To be adequate, this theoretical framework should be able to connect the phenomenal aspects of consciousness and their underlying brain mechanisms. Using Revonsuo's words (Ref. [1], pp. xvi), one "should take very seriously both the subjective psychological reality of consciousness and the objective neurobiological reality" in their intimate connectedness within a single integrated continuum.

Indeed, only an adequate theoretical apparatus can provide cognitive neuroscience with the level of description and explanation necessary to carry out its investigations. In general, cognitive neuroscience is interested in discovering how the brain makes possible and realizes cognitive phenomena such as language, consciousness, attention, memory, etc.: in a word, to have a mental life. In order to achieve this aim, cognitive neuroscience usually tries to find out where in the brain, in which brain areas, a particular cognitive phenomenon is located; what kind of neuron circuit implements it; at which point in time the phenomenon takes place compared to the neural process. Cognitive neuroscience tries then to give an account in physical terms of cognitive, mental phenomena.

It is quite easy to realize that such an account cannot be given without having first formulated a theoretical model that explains how cognitive phenomena are produced, what they consist of, and, more in general, how our mind works. Indeed, in order to identify the brain structures and mechanisms responsible for the production of cognitive phenomena, one needs a criterion by means of which one understands where, what, how and when to look for and to observe. The physical field can be subdivided in so many different levels (the micro-level of the atoms and sub-atomic particles; the medium-level of cells and neurons; the macrolevel of the neuronal assemblies and nets of these assemblies, etc.), and observed from so many different angles (as an isolated unit, as a composite system, as a dynamic structure, etc.) that without a criterion or guide for deciding where, what, how and when to observe, one cannot even start a research. Where should one address it? What should be the more appropriate level of observation of the physical phenomena: the level of the atoms composing neurons, the level of neurons, or the level of the assemblies of neurons? How, and on what basis, could one explain the relationships between the various elements composing each physical level? What criterion should one adopt to analyze the relationships between the different physical levels? More in general, how can one explain the transition from the physical level to the mental one?

What should this theoretical model look like in order to adequately support both cognitive (phenomenal, psychological, linguistic, neuropsychological, neuro-linguistic) data and their neurophysiologic underlying mechanisms? We believe it should be an operational model, that is, a framework centred on the notion of "operation". Let us see the main reasons that led us to believe this:

1) Mental phenomena are not mere copies of the external world, but are the product of the subject's activity. As such they can best be described and analyzed in terms of the operations performed by the subject's mind to produce them.
In general, there is clear evidence in many experiential fields that even basic mental phenomena such as perception, attention and memory do not simply reflect what is "out there", but are the result of specific (voluntary and involuntary) cognitive processes of the subject. For example, well known phenomena in time perception, such as "prior entry" $[8,9]$ and "temporal displacement" (Zeitverschiebung) [10, 11] clearly show that the way the subject perceives the sequence of events is determined not so much by the objective, physical sequence of the events, but by cognitive factors: the way the subject deploy its attention; whether the sequence of events occur within the so called "phenomenal present" [11], which is strictly linked to specific cortical rhythms [12]; and so on. Space perception is similarly determined by cognitive factors [13]. Moreover, very basic sensations such as pain and pleasure exist which certainly do no represent things and objects of the outside world [14].

More specifically, the fact that mental phenomena are not mere copies of the external word is testified by higher-order mental phenomena such as reflective thought, conceptualization and imagination. Indeed, it is always possible to think about, describe, categorize or imagine even the simplest physical situation or object in two or more different ways, and two or more different situations or objects in the same way. Linguistic syntax is nothing less than the most evident way human beings have of bringing forth and realizing this, by variously linking, combining, re-combining and dividing phenomenal elements in various ways.

What all this shows is that the mind does not so much passively duplicate the external world, but rather actively selects, discards and combines sensory, memory and conceptual data according to both inherited and acquired cognitive principles, in order to satisfy the subject's personal motivations, objectives, and attitudes, as well as social and cultural constraints and habits. The human mind is first and foremost an "operating mind".

2) As Ceccato has extensively shown in his work [15-19], what allows one to relate the mind and the brain, the mental field and the physical field - and consequently to compare them, as well as distinguish the former from the latter - are the concepts of activity and operations.

Mental activity (at least, the conscious one; see Ref. [20]) is characterized by the fact that its products coincide with the activity itself, in the sense that they last and are present only as long as the activity itself takes place. Let us consider, for instance, the thought of a burning tree: the thought (that is, the product of your mental operations) is present in the mind only as long as you think about it, and decays as soon as you stop thinking about it (that is, when you stop performing those specific mental operations).

Physical activity in the physical world, on the contrary, is characterized by the fact that its products survive the activity itself, and remain quite visible even after the activity is over: when we burn a piece of wood, we can see the product of the physical activity (the ashes) quite clearly even after it has ended.

The intimate connectedness between consciousness and neurobiological reality mentioned by Revonsuo [1] can then be found by utilizing the concept of "operation": by means of it, we can capture, on the one hand, the kind of activity the 
mind performs when producing conscious mental phenomena, and, on the other hand, the physical, brain activity that is necessary to support mental activity.

Therefore, the most proper way of describing higherorder mental phenomena is by looking for and analysing the operations producing them, that is, by adopting an operational approach (for a more detailed discussion, see Ref. [21-27]). In this sense "operation" stands for the process or series of acts that are limited in time. This provides a basis for discussion of the relative complexity of operations, where there is a more complex operation/operational act that subsumes the simpler ones [27, 28].

Once an operational theory of mental phenomena in general and linguistic thought in particular is developed, it becomes possible to look for the neurophysiological basis of the operations producing them. Neurophysiological research will then be provided with a theoretical framework capable of guiding its investigations in a reasoned and methodical way. In turn, neurophysiological research will have the possibility of either confirming or falsifying the theorized postulates, and in the latter case it will lead theoreticians to modify their hypothesis, or adjust their analyses.

As Silvio Ceccato $[15,18]$ argued many years ago, only an operational model would be able to provide a suitable and viable criterion capable of directing the research investigation of what is considered to be the physical substratum of the mind: the brain. In fact, by analysing and considering our conscious mental world as a hierarchy of carefully organized self-presenting phenomenal patterns (which are both the object and the act/operation at the same time [1, 29]), produced by the activity of some physical system (the brain as a whole, or its parts), it is possible to assign to every single neurophysiological operation some mental property or pattern. In this way, the road is open to the systematic and detailed research of the physical (neurophisiological) basis of the phenomenal world: by subsequent and finer and finer manipulations of the physical brain substratum, one can empirically determine and isolate the system(s) that is (are) responsible for the instantiation of specific phenomenal features or patterns. The opposite strategy is also possible, that is, firstly isolating higher-order mental phenomena such as thought and semantic processing (or some other phenomenal pattern of subjective experience) and secondly trying to identify the neurophysiological pattern that is responsible for them or accompanies them.

The notion of operation, then, is the fundamental and central one in bridging the gap between brain and mind: it is precisely by means of this notion ${ }^{1}$ that it is possible to identify what at the same time belongs to the phenomenal conscious level and to the neurophysiological level of brain activity organization, and mediates between them [27, 30].

In this article, we will present two different but complementary operational approaches to mind and brain: Operational Semantics (OS) and Operational Architectonics (OA). These two approaches had a completely independent origin, and belong to two different fields of research. OS, which was put forward by Benedetti and Marchetti following in the footsteps of Ceccato [16-19], is essentially based on intro-

${ }^{1}$ Importantly, it has to be noticed that operations can be of different complexity [28]. spection and the analysis of linguistic data. This approach, therefore, can be classified between Cognitive Psychology and Linguistics. Among other things, OS has led to the formulation of an operational theory of the nature and structure of linguistic thought, that is, of the kind of reflective thought that lies at the basis of human language, and of which human language is the expression.

$\mathrm{OA}$, on the contrary, is based on the joint analysis of cognitive and electromagnetic (EEG and MEG) data. This approach originated from the work of Kaplan [31-33] and was further modified and developed into a complete theoretical framework by Andrew and Alexander Fingelkurts [26-28, 34-36]. According to this theory, whenever any pattern of phenomenality (including reflective thought) is instantiated, there is a neurophysiological pattern of appropriate kind that corresponds to it $[30,37]$. These patterns (expressed as virtual operational modules) are brought into existence by joint operations of many functional and transient neuronal assemblies in the brain.

The aim of this theoretical paper is to show that these approaches are correspondent to each other through the shared notion of operation, which is central for the higherorder reflective thought/language (OS approach) and the functioning of brain (OA approach). In this paper, firstly, we will consider briefly the main principles of both theories. Secondly, we will illuminate what the supposed correspondence between them could be. And thirdly, we will consider the main implications deriving from the combination of these two approaches, namely the possibility of experimentally and empirically verifying by means of the neurobiological approach the hypotheses put forward, and the analyses performed, by the introspective-linguistic approach.

\section{OPERATIONAL SEMANTICS (OS)}

Since two theories (OS and OA) and their possible correspondence have to be introduced in the restricted space of an article, only the essential outlines of OS are shown here. A more in-depth introduction can be found in the main references $[20,23,38]$. The difference between this kind of semantics and the other kinds of semantics has been variously described: Benedetti [38] for example outlines the difference between OS and Natural Semantic Metalanguage [39-46]; Marchetti [20] outlines the difference between OS (which he also calls Attentional Semantics) and Logical-philosophical Semantics (put forward by authors such as Frege, Carnap, Tarski and Montague) and Structural Semantics (developed by authors such as Hjelmslev, Martinet, Greimas and Saussure); Marchetti [47] highlights the difference between OS and the kind of cognitive semantics put forward by Leonard Talmy. The difference between the principles inspiring OS and the other kinds of semantics is also highlighted by Ceccato \& Zonta [19], who describe the difference between what they call Operative Linguistics and Structural Linguistics, and by Vaccarino [48], who extensively deals with the relationships between his Constructivist Semantics and the other kinds of semantics. Oliva [49] describes the differences between Operative Linguistics and the other main linguistic theories. Finally, and in order to let the reader better understand the theoretical innovations introduced by OS, it has to be noticed that OS differs substantially from the majority of recent psycholinguistic studies (for an extensive review, see 
Ref. [50, 51], not only for the fact that it primarily deals with, and privileges, the semantic aspect of language over the syntactic one, but also because it offers a functional model that could be applied equally well to the comprehension stage of language as to the production stage of language: in this sense, OS represents in our view an important improvement on , and integration to, current psycholinguistic studies.

As everybody knows, thought is not accessible with objective methods. It is accessible only subjectively through first-person perspective or, indirectly, by means of language. However, what is accessible is only the content of thought, not its mechanisms [1]. These mechanisms are shrouded in a deep mystery. Neural Science, despite its progresses, does not seem to be going to reveal this mystery (at least at present). OS proposes to study these mechanisms by adopting some new fundamental theoretical presuppositions and a methodology, which is both introspective and linguistic. What OS allows us to study is the higher-order reflective linguistic thought, that is, what language is the expression of (for the sake of simplicity, from now on we shall use the expression "linguistic thought"). Linguistic thought, despite being just one kind of thought, is nevertheless the prevalent one, at least in the human being who has already learnt to speak.

We believe that the best way to introduce OS is exactly to consider language itself. So, let's take a fragment of language at random. For example, the beginning of one of the most famous books in the world: "Pinocchio".

Once upon a time there was...

- A king! - my small readers will say at once.

No, children, you are wrong. Once upon a time there was a piece of wood.

It was not a luxury wood, but a simple stack piece, one of those pieces we use to put in stoves and fireplaces in winter to light fire and to heat rooms.

Every discrete element of language, that is, every word, designates at least one meaning (in many languages, many single words designate more than one meaning together, like, for instance, the basic meaning plus the plural). Therefore, each word designates one (or more) "atoms" of thought. Let's ask ourselves what these "atoms" are, what their nature is. As far as their nature is concerned, first of all it seems that the meanings of words can be divided into at least three categories.

1) In the passage we have chosen, there are words that, at first sight, seem to designate something physical (or, at least, mainly physical). These words are: "children", "wood", "stack", "stoves", "fireplaces", "winter", "[to] light", "fire", "[to] heat", "rooms". It is easy to realise that such words are so many that they make up probably most of the lexicon of any language.

If we consider this class more in depth, however, it does not seem homogeneous. Words such as "robin", "bird" and "animal", for instance, seem all to belong to this class, but certainly they express an increasing level of "abstraction" (therefore, something mental). Words such as personal pronouns ("I", "you" etc.), even if they undoubtedly designate something physical, are certainly more "abstract" than the names of the people they indicate in turn, for example "John Smith". But, apart from these considerations, what we want to highlight is that there is a big class of words that have an evident and important reference to something physical.

2) Then, there is another class of words that indicates things that we can collectively call "psychical", that is, feelings, emotions, moods etc. (love, hate, fear, anger etc.). These words are much less numerous (in the passage chosen there is not one of them).

3) Finally, there is a third class of words (or, in many languages, morphemes) that seem clearly different from the ones of the first two classes. In the passage chosen they are: the verbs "to be" and "to have", the article "a", the prepositions "upon", "at", "of", "in", "to", the demonstrative adjectives "that" and "those", the negations "no" and "not", the conjunctions "and" and "but", the numerals "once" and "one", the adverb "there" and the morpheme "-s", which indicates the plural. These words do not, or only minimally, seem to refer to anything physical or psychical. In the vocabulary of a language they are all the "grammatical" words, that is:

- prepositions (with, of, to, at, from, by, in, for, on, between, among etc.) and conjunctions (and, or, if, because, but etc.);

- interrogative-indefinite-relative pronouns or adjectives (who, what, which, whoever, whatever, whichever etc.);

- demonstrative adjectives and pronouns (this, that, other, the same etc.);

- main adverbs of place, time, manner etc. (here, there, where, when, how, why etc.);

- pronouns/adjectives of quantity (all, many, some, few etc.);

- negation (not, no, in- or un- as a prefix);

- numerals (one/first/once; two/second/twice; three/third etc.);

- fundamental verbs like "to be", "to have", "to get" etc.;

- most morphemes of the large number of languages that have a more or less rich morphology (the ones which indicate cases, in languages that have cases; the number of nouns and, in many languages, of adjectives; moods of the verb etc.).

In the passage chosen there are also two other words, "small" and "piece", which, even if they are not properly considered "grammatical", seem to be of the same kind (other examples can be: "big", "high", "low", "beginning", "end" etc.).

It is easy to realise that the number of items composing this class is quite limited (probably, they are more than the items of the second class, but surely much less than the ones of the first class), but, as a class, they are used in an extremely frequent way. If we choose samples of language at random, we will realise that this class is, in almost all cases, the main component of sentences and that it is absolutely indispensable in order to speak, that is, to make any speech up. Therefore, it is logical to consider it the fundamental structural component of language, and therefore of linguistic 
thought. We maintain that until we understand the nature of the meaning of these words, we shall not be able to understand the nature and the structure of linguistic thought.

Well, what do these words and morphemes indicate? In some cases, it may seem that these words, even if they do not indicate something physical or psychical, indicate relationships amongst physical things (in sentences such as "bottle of wine", "he has a moustache" etc.) or features of physical things (in sentences such as "a large table"). Nevertheless, the same identical words may be used without problems in situations that have nothing to do with the physical world (for instance, we may say "stream of consciousness", "to have an idea", "a large number" etc.). Therefore, the answer to the question must be a different one.

Naturally, linguistics tried to give an answer to the aforesaid question $[52,53]$. The solutions proposed so far seem unsatisfying. In order to realize this, it is sufficient to examine the definitions of these words that can be found in dictionaries. They use tautologies (for example, "not" is defined as "negation") or false synonyms (for example, "to have" would mean "to possess, to own", "to keep", "to get, to obtain", etc.) or they send us from one word to another word and then back (for example, the verb "to look for" is defined by means of the verb "to find" and vice versa). As far as prepositions are concerned, they are generally said to have a lot of meanings, that is, they would indicate many kinds of relationship (such as place, time, manner, cause, means or instrument, company or union, origin etc.). It is easy to object that it seems improbable that words, which occur so frequently and are so indispensable, have so many meanings. It is more likely that prepositions have only one, more general meaning (that is why it is so difficult to determine it), and that the many relationships grammar speaks about are only specifications, just introduced by grammar itself, which are included in this more general meaning: for example, it is more likely that the preposition "with" does not designate the relationship of company or union, manner, cause etc., but something more general in which the relationship of company or union, manner, cause etc. are included. In fact, several linguists themselves admit, more or less openly, that the definitions given of these words are unsatisfying [52, 53].

A completely new solution to this problem comes from OS. This kind of approach was developed, in the 50s-70s of last century, by S. Ceccato (1914-1997). Two of the authors of this paper, Benedetti [21-23, 38, 54-56] and Marchetti $[20,24,25,57-60]$, have deeply modified and developed it (because of this, they use a name that is different from the original ones - such as Operational Linguistics and Operational Methodology - used by Ceccato). The fundamental thesis of OS is that these words designate sequences of mental operations (the name "Operational Semantics" derives from this), amongst which the ones of attention play a key role.

Ceccato called "mental categories" these sequences of mental operations, an expression that is also adopted by OS. We must notice the fact that this use of the expression "category" is completely different from the use made in Cognitive Psychology and Linguistics. Typically, Cognitive Psychology and Linguistics use the expression "category" to highlight the fact that, since many objects of the physical world share common features, but are not identical, we create classes by means of a mental process of abstraction [61-64]. On the contrary, OS calls "mental categories" the meanings of the words such as the ones we listed at point (3).

As we pointed out, according to OS, mental categories are made up of mental operations, which were called elemental mental operations by Ceccato. Also in this case, it must be highlighted that the use by OS of the expression "elemental mental operations" differs from the use made in cognitive sciences: while for the former it denotes only "elemental operations that make up mental categories", for the latter it has a wider meaning, denoting also some other kind of operations that may be considered "elemental", such as, for example, basic operations of perception. For this reason, in this paper we shall use, as much as possible, the more specific expression "elemental operations that make up mental categories", or its acronym EOMC.

Below we shall try to summarise very briefly how, according to OS, mental categories are formed starting from EOMC and how linguistic thought is made up starting from mental categories, so that the reader can understand the experiments proposed in the last part of this paper.

Ceccato hypothesized that attention can only be in two states (attention waiting for something to be focused on, and attention focusing on something) and that the structure of the mental categories is made up of the various possible combinations of a progressively increasing number $(2,3,4$, etc.) of these two states. This hypothesis gave poor and controversial results in the analysis of mental categories. Nevertheless, Ceccato gave also some other sketched descriptions of the structure of several mental categories. Starting from these descriptions, Benedetti [22, 23] and Marchetti [20] have proposed a set of EOMC that is more complex than Ceccato's, and have consequently put forward new analyses of the fundamental mental categories.

Benedetti and Marchetti's proposals include both operations of attention and other kinds of operations, most of which have been repeatedly described in Cognitive Psychology. Starting from the seminal works by James [65] and $\mathrm{Ri}-$ bot [66], attention has been variously analysed and described: Posner [67, 68] and Posner and Cohen [69], for example, specifically describe the operation of orienting attention and the three elemental operations composing such an operation: engaging on a target, disengaging from it, and shifting to a new target; Jonides [70] describes the way attention can be focused at variable levels of size, being set either widely across a display of objects or narrowly to the size of a single object; La Berge [71] analyses how attention can be focused at variable levels of intensity; La Berge [72] describes how attention can be sustained or maintained for variable, though limited, amounts of time; Pashler [73] describes the different involvement of attention during the perceptual processing stage and more central, post-perceptual stages. The works by Braga-Illa [74-76] and Denis [77] describe in an extensive and quite exhaustive way the bulk of studies on representation in various scientific fields (psychology, sociology, logic, artificial intelligence, etc.). As to memory and its various forms and characteristics, see Baddeley [78], Baddeley and Hitch [79], Cowan [80, 81], Miller [82], Oberauer [83] and Oberauer et al. [84]. 
The new idea we propose is that by means of these operations we can account for the meaning of the words listed at point (3), hence for the nature and structure of linguistic thought. The list of the EOMC that Benedetti proposes is the following.

\section{Operation of Attentional Focalisation (AF)}

This operation produces the "selection", or "highlighting" of its object with respect to all the rest [65]. AF can widely vary in extension (therefore, we can focus our attention on an object, a part of it, or several objects). The focus of attention can move from an object to another one, or from a part of the field to which it is applied to another one. Moreover, AF can be maintained for variable, though limited, amounts of time. Attention can be applied not only to objects, but also to the so-called "maps" [38]. The main maps are the spatial map and the temporal map, that is, our mental representations of space and time. In this way it is possible to account for the structure of the mental categories related to space and to time (for example: "place", "where", "here", "there", "high", "short", "wide", "narrow", "left", "right", "now", "before", "after", "during", "when" etc.). (For the importance of attentional selection in the construction of space, see also Carstensen [85-87]).

\section{Operation of Attentional Discarding (AD)}

By means of this operation we exclude or discard something, keeping anyway in mind the fact that attention was focused on it before (this operation is different from simply stopping focusing our attention on an object in order to focus on something else).

\section{Operation of Representation (R)}

The operation of representation is the act of thinking about something which is not present. This is what we do when, hearing for example a word, we pass to its meaning, which was previously memorised. Sometimes the formation of a mental image of the object follows the understanding of the meaning.

\section{Operation of Comparison (C)}

When this operation is performed, we compare two (or more) objects that are focused by attention and borne in mind. Even though comparison implies operations of AF and presence keeping, we believe that it has to be considered as a separate function. This is the reason why we call it "extraattentional" operation.

\section{Presence Keeping (PK)}

In common language, this operation is referred to as "bearing (or keeping) something in mind". This operation is surely strictly related with the well-known concept developed by Cognitive Psychology of "working (or active) memory" [78-81, 83, 84]. We can sense this operation very well when, looking at two distinct objects, $A$ and $B$, firstly we name them separately, and then we say " $A$ and $B$ ": in the latter case, we focus our attention on $A$ and we keep it present while focusing our attention on $B$.

\section{Operations of Memory (MO)}

Memory surely plays a key role in our mental life: by means of it, we fix and recall both brief and long-term memories continuously. Apart from all of this, Benedetti thinks that memory operations are part of the structure of some mental categories [22, 23, 38]. Therefore, we list them amongst the basic mental operations that make up mental categories. Also these memory operations are distinct from the ones of attention.

As we have said, our hypothesis is that the meanings of the "grammatical" words, which represent the majority of mental categories, are sequences of EOMC. Let's briefly consider some simple examples ${ }^{2}$.

In the case of the conjunction and, as already mentioned, we focus our attention (AF) on something (say $A$ ) and we keep it present $(\mathrm{PK})$ while focusing our attention on something else, $B$. In this way $B$ is "tied" to $A$. In the case of the conjunction or, firstly we focus our attention (AF) on an object $A$ and then we discard (AD) it in order to focus the attention on another one, $B$. Therefore, $A$ is excluded when $B$ is taken into consideration: an alternative between the two objects is so created.

In the case of the preposition with, first we focus our attention on an object $A$, then the attentional focalisation also extends to another object $B$, because $B$ is in such a relationship with $A$ that attention is induced to focus $A$ and $B$ as a unity, together. For example, we say, "bottle with cork" when the cork is in the neck of the bottle. We have to notice that this analysis explains very well the fact that in many languages this preposition is used to express both the relationship of company or union between two things and the one of means or instrument between an activity and an object. Indeed, both when we say, for example, "cup with handle" and when we say, for example, "to write with a pen", what appears to our attention is an object which is in such a relationship with another one that our attention is induced to focus on both objects together, as a unity. In fact, the handle is joined to the cup and therefore as long as we look at the cup we also see the handle; and as long as we watch the action of writing we see the pen.

Also in the case of the meaning of the genitive case (expressed in English with the preposition "of", the possessive case or word order) we refer to a situation in which an object is in such a relationship with another object that attention is induced to focus also on the latter. However, when using the genitive case, we keep mentally present such a relationship between the two objects, but then we focus attention only on the second object. For example, if, looking at a man with a black hat on his head, we say "there is a man with a hat" and then add "the man's hat is black", in both cases we keep present the fact that the hat is in such a relationship with the man that attention is induced to focus on both objects (the hat touches the man), but when using the genitive case attention then focuses only on the hat (in order to talk about the hat and say that it is black). This analysis explains very well the fact that the genitive case is used when between two objects there are relationships such as: possession ("John's car"), work/author ("picture of Raphael"), part/whole ("the branches of the tree"), belonging to a group ("a friend of mine"), feature/object ("the colour of the dress") etc.

\footnotetext{
${ }^{2}$ The most important mental categories have been identified by using: the list of "semantic primitives" of "Natural Semantic Metalanguage" [39-46], the Swadesh list (a list of basic words, common to most languages) and the list of Indo-European roots.
} 
The category of negation ("not", "no", "in-" or "un-" as a prefix) indicates the discarding (AD) of the representation (R) of a meaning. If, for example, we say, "John's car is not red", we mean that the representation of the meaning "red" concerning John's car (a representation that was prompted by a previous event, such as for example the question: "Does John have a red car?") is discarded.

The categories which, what and who indicate that attention is firstly focused (AF) on a group of two or more elements, which are considered equal (C), and then focused on one of them while discarding (AD) the remaining objects, bearing in mind (PK) the origin of the first one. If, for example, we are looking at some books, and someone asks us "which book do you want?", we will realize that after having focused our attention on the group of books, we focus on one of them while discarding the others, but bearing in mind the fact that the book chosen comes from a group of similar elements (that is, a group of books).

The category "how much" is produced by means of the operation of counting, that is, by means of a series of operations of focalization of attention (AF), one following the other, on each object of a group of objects considered equal $(\mathrm{C})$, bearing in mind $(\mathrm{PK})$ the preceding objects each time we add a new one. Each successive repetition is named by a different name (these are the single numbers: "one", "two", "three" etc.). The word number indicates each one of these repetitions without specifying which one, while how much indicates that attention must be focused on the final result of counting. The category of plural instead indicates that we have simply carried out subsequent attentional focalizations on things considered equal, but without associating a conventional name of a progressive series (that is, a number) to each of them. For example, if, when looking at a scene in which there are an apple, a pear, a plum and a peach, we say "there are four fruits", this happens because, firstly we have considered the apple, the pear, the plum and the peach as elements that are equal (that is, as "fruits"); secondly, we have focused our attention on one of them associating a conventional name ("one") to it; thirdly, while bearing in mind this, we have focused our attention on a new element associating another conventional name ("two") to it; and so on. If instead we say, "there are some fruits", we have carried out the same operations, but without the association of a progressive series of conventional names.

We conclude this brief series of examples of analyses of mental categories with two verbs: "to have" and "to get". Their meanings are so general that dictionaries usually try to capture them by defining each entry with a very long list of verbs: for example, "to get" would mean "to obtain", "to receive", "to understand", "to become" etc. However, these lists are nothing else but collections of more "specialised" verbs whose meanings are included in the more general meanings of "to have" and "to get". The meanings of "to have" and "to get" are so general because both these verbs designate the same relationship as the one designated by the preposition "with" (first attention focuses on an object $A$, then attentional focalization is extended to another object $B$ because the latter is in such a relationship with $A$ that attention is induced to focus $A$ and $B$ as a unity, together). The difference with the preposition "with" is that, in the case of these two verbs, as in all verbs, we see the situation from the temporal point of view, which entails that we keep our attention continuously or repeatedly focused on the situation, and feel its incremental work [88]. In the case of the verb to have, the result is something static. For example, "that man has a moustache" means that when we focus our attention on his face we also see a moustache and this remains constant throughout time. On the contrary, in the case of the verb to get, the result is something dynamic. For example, "to get the pen" means that our hand comes in such a relationship with the pen that if we look at the hand we also see the pen (the pen is in the hand), while before there was not such a relationship.

Now that we have introduced some analyses of mental categories, we can explain how, according to our theory, mental categories allow us to produce linguistic thought. Let's consider the following words: "apple", "pear", "red", "and", "or", "with". Let's try to represent each of the meanings of these words in an isolated way. This is easy for the first three words, while for the other three we have a clear sense of "incompleteness". We sense very well that these words require something that precedes them and something else that follows them. In other words, their function is to "tie" two other elements to each other. According to our theory, linguistic thought is made up of two fundamental kinds of elements:

1) correlators

2) correlata

Correlators are the elements that have the specific function of tying the other elements of linguistic thought. They are the mental categories designated by prepositions, conjunctions and some of the so-called cases (genitive, dative etc.), in languages that have cases (in languages that have no cases their meanings are expressed by means of prepositions). Correlata are the elements that are "tied" by a correlator. According to OS, even though the meanings of isolated words (such as "apple") are a kind of thought, there is actual linguistic thought only when we "tie" or "correlate" more than one meaning to each other, that is, when we say, for example, "apple and pear", "red apple", etc.

The two correlata that are tied by a correlator are called "first correlatum" and "second correlatum", respectively, according to the order in which attention focuses on them. The whole structure so formed is called correlation or correlational triad and we represent it graphically in the following way:

\begin{tabular}{|l|l|}
\hline \multicolumn{2}{|c|}{ correlator } \\
\hline first correlatum & second correlatum \\
\hline
\end{tabular}

In the case of the example "pear and apple", we shall have this correlation:

\begin{tabular}{|c|c|}
\hline \multicolumn{2}{|c|}{ and } \\
\hline pear & apple \\
\hline
\end{tabular}

Besides prepositions, conjunctions and some cases (in languages that have cases), there is another correlator, which is extremely important. Its structure is the same as the one of the conjunction "and" (attention focuses on $A$ and $A$ is borne 
in mind while attention focuses on $B$ ), but in this case $A$ and $B$ do not remain separate, but they "combine" together. This happens because $A$ and $B$ are in some way complementary. For example, $A$ is an object that can exist on its own and $B$ a possible feature of it (correlation substantive-adjective); or $B$

\begin{tabular}{|l|l|}
\hline \multicolumn{2}{|c|}{-} \\
\hline green & leaf \\
\hline
\end{tabular}

is what may happen to $A$ in time (correlation subject-verb); or $A$ is an activity and $B$ something the activity can be performed on (correlation verb-object); etc. We represent the implicit correlator graphically by means of a horizontal bar:
Since this correlator is, as we can easily understand, the most used of correlators, it is convenient not to express it with a word and to indicate its presence either simply putting the two words that it correlates one after the other (when this is possible) or using marks of the words (English has very few marks of this kind, but many languages have several of them: for instance, in the Italian sentence "bottiglia di vino nuova", which means "new bottle of wine", the two "a" that are underlined are marks of the feminine gender, which indicate that the adjective nuova, "new", has to be related to bottiglia, "bottle", not to vino, "wine"). Because this correlator is not expressed by a word, it has been called "implicit correlator". Nevertheless, it is really implicit only when no lin-

\begin{tabular}{|l|l|}
\hline \multicolumn{2}{|c|}{ - } \\
\hline John & reads \\
\hline
\end{tabular}

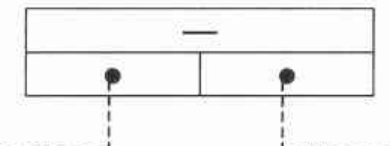

(the dotted line that starts from the line that separates the two lower boxes of a correlation and that ends with the symbol "•" placed in one of the two lower boxes of another correlation indicates that the first correlation is one of the correlata of the second correlation). We call this theory correlational theory of linguistic thought. Obviously, it is also a linguistic theory, but the facts that a) it is above all a theory about the nature and structure of thought; b) it makes a clear distinction between correlators and correlata; c) it considers linguistic thought a non-linear "network", based on units necessarily composed of three elements - one element that ties and two elements that are tied (even if sometimes the former is not expressed) - make it a linguistic theory that is deeply different from all other linguistic theories.

The set of hypotheses forming OS, which we have very briefly summarised here, have been put forward through methods of both an introspective and a linguistic kind (analysis of the contexts in which words expressing mental categories occur). These very same linguistic data also allowed us to verify the validity of the analyses carried out. The study of the gestures that sometimes accompany the verbal expression of mental categories provided further evidence for our hypotheses [89]. Unfortunately, up to now there was no real opportunity to relate OS theory to a biologically based framework, which describes the properties of reflective consciousness at the neurophysiological level of brain organization, and to test OS's hypotheses by means of neurobiological methods. OA is a neurobiological theory, recently developed by two neuroscientists - the Fingelkurts brothers, which has a putative correspondence with the introspective-linguistic OS theory by Benedetti and Marchetti and offers a methodological way to test the common predictions of both theoretical frameworks.

Summarising, the fundamental theses/predictions of OS, which make it a deeply different semantic theory from the others, are the following.

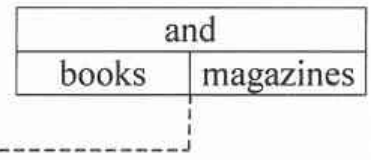

guistic element (whether word order or word marks) expresses it, that is, only when it can be inferred by the general sense of the sentence. For example, in the two expressions "empty whisky bottle" and "Scotch whisky bottle" only the sense of the sentence tells us which noun the two adjectives "empty" and "Scotch" refer to.

According to OS, correlation is the basic unit of linguistic thought. Linguistic thought in fact is a "network" formed by correlations (correlational network) in which a correlation acts as a correlatum of another correlation. Therefore, the sentence "John reads books and magazines", for instance, has the following structure of thought:

1) According to the wide and in-depth approach of Wierzbicka $[40,41]$, most words of a language can be defined by means of words of the same language, but there is a core of fundamental words (which Wierzbicka calls "semantic primitives") whose meaning cannot be defined by means of words. This central core is mainly made up of the "grammatical" words. According to OS, we can account for the meaning of these fundamental words only by "getting out of language". In fact, the fundamental thesis of OS is that the meanings of these words (which OS calls "mental categories") are sequences of elemental mental operations, amongst which the ones of attention play a key role. These elemental mental operations (which OS calls "elemental mental operations which make up mental categories", or EOMC) have been repeatedly described in Cognitive Psychology. The prediction of OS that the grammatical words are constituted by sequences of EOMC can be experimentally tested and ascertained thanks to the methods and techniques developed by OA. In this work we propose some experiments aiming at verifying such a prediction.

2) Although linguistics has often, more or less explicitly, considered the aforesaid words (or morphemes) as having a complex meaning and polysemous (think, for example, of the prepositions), these words are unique and children learn them very early. OS proposes a holistic and organic theory of the meaning of these words where they are considered, in agreement with these two facts, as having a simple and (substantially) unique meaning. This meaning is simple because it is given by sequences of basic mental operations, that is, lies at the most general and de-contextualized possible level. That is, words such as "and", "or", "with", "of", etc can relate any kind of things (physical, psychical, mental things) to each other because they do not designate a specific physical or psychical or mental relationship, but something more general, that is, 
a particular way of mental operating where attention plays the key role. Furthermore, this meaning is (as a principle) unique (as well as the word that expresses it is unique) because these words do not express, contrary to what has being traditionally generally maintained, the various particular relationships that there are between the things these words relate (for example, in the case of the preposition "with", the relationship of company or union between two things, the relationship between an activity and its instrument, etc), but something more general where these relationships are included. As we can see, OS proposes a theory of the meaning of these fundamental words that agrees perfectly with two incontestable facts: each of these words, despite its various supposed meanings, is unique and all these words are basic elements that children learn very early. On the contrary, linguistic tradition has generally maintained that these words are very polysemous (that is a very improbable thesis, in our opinion) and their meaning is very complex (this disagrees sharply with the fact that these words are amongst the first that children learn to use perfectly). The prediction of OS concerning the univocity of the grammatical words can also be experimentally verified.

3) According to Ceccato and Zonta [19] and Vaccarino [90], EOMC are mainly represented by attentional states and memory. Contrary to such a hypothesis, OS predicts that also some other elemental mental operations are involved. This prediction can be experimentally ascertained through the neurobiological approach of OA.

There are other theses/predictions of OS that we cannot take into consideration in an article such as this. They are extensively discussed in Benedetti's work ([23], pp. 232-235; [38], pp. 21-24). Here we simply mention them:

4) OS proposes a simple and unique definition of grammatical terms such as "noun", "subject", "object", etc. It is a well-known fact that the definition of these terms has always been problematic. The definition provided by OS works perfectly in all cases where the various traditional definitions fail.

5) OS proposes an answer to the problem of whether human linguistic ability is innate or acquired. This answer (which is different from the traditional ones and intermediate between them) agrees perfectly with the available data.

6) OS, following its presuppositions, proposes a theory about the main reason for the difference between human language and animal communication.

7) OS proposes a theory about the linguistic universals that could steer the research in this field in a new direction.

\section{OPERATIONAL ARCHITECTONICS (OA)}

As the details of the OA theory are beyond the scope of this paper, here we will only concentrate on some essential aspects which are important for the current discussion (primary references for $\mathrm{OA}$ theory are Fingelkurts and Fingelkurts [26-78, 30, 34-36]. In brief, the OA theory assumes that the level of organization at which cognition, phenomenal consciousness, and, in particular, reflective consciousness (in the form of linguistic thoughts) reside might be the highly organized macro-level electrophysiological phenomena (metastable operational modules) in the brain, which are realized by the coordinated electrical activity (operational synchrony) of many neuronal assemblies dispersed throughout the brain [26, 28]; for a similar view, see Revonsuo [91]. The activity of these neuronal assemblies is "hidden" in the complex nonstationary structure of the biopotential brain field - i.e., EEG (for the review, see Ref. [27, 34, 36]. At first glance the OA theory has some similarities with other important related theoretical frameworks, such as, for example, Dynamic Core [92], Resonant Cell Assembly [93], Global Workspace [94] theories, Framework for Consciousness [95] and Philosophy of Mind [96]. However, the OA theory has several crucial and important differences from all of them (for some argumentation, see Ref. [36]).

Let us briefly observe the main postulates of the OA framework:

1) One, and probably the most important one, of the different operations of the neuron is to process the electric currents which arrive on its dendrites and transmit the resulting electrical current to other connected neurons using its axon. This "blind" neurophysiological operation is, at the same time, the elemental physical operation of the brain (Table 1). Such operations have a fully neurophysiological ontology and they are completely NONconscious phenomena, which, according to Searle [97], have no mental/subjective ontology whatsoever.

The single neurons (highly distributed along the cortex) can quickly become associated (or dis-associated) by synchronizing their operations and giving rise to transient neuronal assemblies. Here the emphasis is put not so much on the anatomical neural networks (as they are conceived in classical concepts [98], but rather on the functional interrelations of brain cells - transient neuronal assemblies [99]. Each of these functional assemblies represent/execute discrete elemental cognitive operations which process/present different attributes of objects, environmental scenes, or some other stimuli, including phenomenal objects of subjective experience [30, 35]. Thus, functional neuronal assemblies support discrete elemental brain operations, some of which may have already phenomenal/subjective ontology in addition to the neurophysiological one (Table 1).

It has been shown that such neuronal assemblies have a transient dynamical existence (i.e. a functional life-span), which usually persists during short (millisecond) time intervals [100, 101]. These intervals represent the time needed for the neuronal assembly to execute/present a particular operation. It has been shown experimentally and in computational models that such intervals are characterized by fixed states of neuronal assemblies which are separated by rapid transitions [102]. Within the rapid transitional period the whole neuronal assembly can swiftly be rearranged [103].

At the EEG level these operations of the neuronal assemblies are reflected in the periods of the EEG quasi-stationary activity within different frequency ranges, registered from different brain locations (for reviews, see Fingelkurts and Fingelkurts [26, 27, 36] and Kaplan et al. [104]).

2) The temporal synchronization of different brain operations executed by different local neuronal assemblies simultaneously (operational synchrony) gives rise to a new level 
Table 1. Hierarchy of Brain/Mind Operations and their Relations to Different Levels of Brain Organization

\begin{tabular}{|c|c|c|c|c|c|c|}
\hline & & single neuron & $\begin{array}{l}\text { single neuronal } \\
\text { assembly }\end{array}$ & $\begin{array}{l}\text { single OM (several } \\
\text { sinchronized } \\
\text { neuronal assemblies) }\end{array}$ & $\cdots$ & $\begin{array}{c}\text { complex OM (integrated several } \\
\text { simple OMs) }\end{array}$ \\
\hline \multirow{2}{*}{ 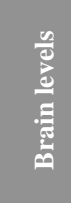 } & Physiological & elemental & complex & more complex & $\ldots$ & very complex \\
\hline & $\begin{array}{l}\text { Higher-order reflective } \\
\text { thought }\end{array}$ & n.a. & n.a. & elemental & $\ldots$ & very complex \\
\hline \multicolumn{7}{|c|}{ n.a. - Non applicable } \\
\hline \multicolumn{2}{|c|}{ OM - Operational modules } & & & & & \\
\hline
\end{tabular}

of brain abstractness - metastable brain states [26-28]. These states are metastable because the neuronal assemblies which constitute them perform/have different operations/functions and each does its own inherent "job" (thus expressing the autonomous tendency), while still being, at the same time, temporarily entangled among each other (and thus expressing the coordinated activity) in order to execute a common complex operation or a complex cognitive act of a higher functional hierarchy [27]. As has been proposed by Kelso [105], metastability relates exactly to the phenomenon of a constant interplay between the autonomous and the interdependent tendency (see also Ref. [106]).

Quantitatively such phenomenon is assessed through the measure of synchronization of EEG segments (structural synchrony) obtained from different brain locations [26]. These metastable brain states or functional Operational Modules $(O M)$, as we name them, may underlie the realization of brain complex macrooperations (Table 1) - cognitive percepts, phenomenal objects, and reflective thoughts within the operational space-time continuum [30,35].

The key point here is that OMs have a more complex structure than the operations which constitute them. However, OMs carry less fine-grained information, since only the essential information for the emergent cognitive percept, phenomenal object, or reflective thought is preserved. For example, in the case of a visual perception, a large amount of information (intensity of the stimulus, lightness, colour, shape, size, proximity, texture and so on) is represented and processed by different neuronal assemblies, but at the higher level of abstractness (metastable OMs) the phenomenal image of an 'airplane', for instance, is presented. Thus, in accordance with the information theory of Shannon [107], the operational synchrony process 'abstracts out' the information carried by OMs, meaning that OMs are not sensitive to the original raw (neurophysiological) data anymore, but only to the spatial-temporal pattern of activation that is embodied in the involved neuronal assemblies. So, the information that remains is only an abstraction of certain aspects of the original data, including physical (non-mental) processes in the brain.

The sequence of these metastable OMs thus may represent the stream of consciousness (for details see the second part of Fingelkurts and Fingelkurts [26]). The main idea is that the structure of the electrical brain field (EEG), the structure of cognition, and the phenomenal structure of consciousness, all have the same organization: the succession of discrete and relatively stable periods (metastable OMs, cognitive acts, or thoughts, correspondingly) separated by rapid transitive processes (abrupt changes between OMs, cognitive acts or thoughts, correspondingly)[30].

3) OMs (being by themselves the result of synchronized operations going on in distributed and local brain structures) could be operationally synchronized between each other (on a new time scale), thus forming more abstract and more complex $O M$ which constitute new and more integrated phenomenal experience (Table 1; see Ref. [28, 36]. We argue that each of the new OMs is not just a sum of simpler OMs. Rather, the more complex OM is most naturally a union of abstractions about simpler OMs. Complexity hierarchy enables the brain to build complex phenomenal patterns/objects from primitive ones so that the semantic value of the complex representation is determined by, and dependent on, the semantic values of the primitives [28]. Such interpretation is consistent with some ideas established already by the early philosopher Thomas Aquinas (reprint [108]), who concluded that single events in the material world are not knowable, and that knowledge comes only through abstraction and generalization from the "phantasmata" of raw sensory impacts.

In the end, such a process may lead to the generation of the most complex mental state, whereby visual, auditory, perceptual, bodily, emotional, cognitive, and other subjective experiences are unified. This state may well correspond to the personal "self" or even to a broader unified experience such as that of "subject" (for the distinction between self and subject, see Ref. [1]). Since also at this top level of abstractness (reflective consciousness) we do not yet have direct access to the brain processes, this subjective (conscious) experience seems so strange and mysterious to us [30].

4) Also the reverse process is possible - when a complex phenomenal pattern, object, or reflective thought (represented in the brain by complex OM) guided by attention is decomposed into several simpler phenomenal parts (OMs), which in their turn may be further decomposed into even simpler ones $[27,28]$. The price for this decomposition is a 
narrowly focused attention and consequently the focused reflective conscious state [1].

\section{CORRESPONDENCE BETWEEN OS AND OA}

It is a fact that human language production and its phenomenal self-presentation are caused by neuronal activity and any speech signal necessarily activates neurons in the brains of listeners when being perceived [6]. Therefore, there should be a link between the structure of the electromagnetic brain field (EEG/MEG) and the structure of the higher-order reflective (linguistic) thought, whereby both of them, although seemingly worlds apart, must be intimately connected and mirrored in each other. However, owing to the enormous complexity of language and the brain functional structures, the subject of the putative correspondence between linguistic mental and neurophysiological brain levels has not been yet addressed directly.

At the same time, developments of recent years in the understanding of psycholinguistic [7, 20-23, 47, 54-56, 59, $60,109,110]$ and brain $[6,26,27,31,36,101,104,106]$ functioning have enabled researchers to identify and eventually to start experimentally to study the parallels between linguistic and brain levels within the same theoretical and methodological framework. To do so, the explanation should be made within the terms of a phenomenon that is shared by both organizational levels of the brain (phenomenologi$\mathrm{cal} /$ mental and neurophysiological/biological) [30, 37].

We believe that the concept of "operation" is the required shared fundamental reference which provides us with a starting point for the conceptual integration and a unified research program. Both, the material neurophysiological organization that characterizes the brain and the informational order that characterizes the mind necessarily involve such events as operations at their cores. Generally, operation is broadly defined as the state of being in effect (for further discussion, see Ref. [27, 28]. It should be stressed that this is so regardless of whether this process is conceptual/phenomenal or physical/biological. In fact, everything which can be represented by a process is an operation. Understanding of the operation as a process and considering its combinatorial nature, seems especially well suited for describing and studying the mechanisms of how information about the objective physical entities of the external world can be integrated, and how unified/coherent phenomenal objects or thoughts can be presented in the internal subjective world by means of entities of distributed neuronal brain assemblies. It is only at this level of integration (through functional isomorphism principle) $[26,34,37]$ that we may hope to relate and bridge the gap between linguistic level on the one hand and empirical evidence of its brain implementation on the other [30].

Up to date there are only two theoretical frameworks that explicitly aim to describe, measure and model the mind (OS theory) and brain (OA theory) operations involved in the complex human higher-order reflective consciousness (thoughts) which is governed by the brain.

According to OS theory, reflective/linguistic thought is always operational (made up of operations) and OS explicitly defines the structure of linguistic thought. This structure is characterized by correlators, correlata, and by a hierarchy of operations of increasing complexity. Likewise, in OA theory the brain functioning is also always operational (made up of operations) and the structure of the brain functioning is also characterized by a hierarchy of operations of increasing complexity and connections between these different operations. The basic idea is that the synchronized brain activity produced by local neuronal assemblies is linked to the required operation (or operational act) and only those local activities evoked by common objects, scenes, or tasks are bound together in dynamically formed metastable OMs [30, 36]. However, the whole level of OS description (elemental operations, categories, maps, and correlational networks) corresponds to the level of OMs (or set of them) of different complexity within the OA theory (see Table 1).

Below we shall propose some possible experiments which can shed light on the correspondence between the main postulates of OS and OA theories. The results of such experiments will either support the initial hypotheses and ideas, or not (and then the theoretical tenets should be modified). Altogether, this research program should give us a profoundly improved understanding of the complex linguistic thought processes, their putative modular architecture and their neurobiological implementation.

\section{EXPERIMENTS AIMING TO TEST A PUTATIVE CORRESPONDENCE BETWEEN OS AND OA}

As we have seen, according to OS, linguistic thought has two components: 1) representations or perceptions of physical and psychical things; 2) mental categories. Also the representations (or perceptions) of physical or psychical things can be products of operations. For example, the perception of a visual object seems to need the integration of features such as form, colour, movement etc., which are processed in a parallel way in distinct brain regions. The OMs identified by $\mathrm{OA}$ could be either the expression of binding operations of this kind, or of other kinds of operations. Nevertheless, OMs (or some of them) could be the expression of higherlevel operations, such as the basic operations of linguistic thought theorized by OS. In this section, we shall try to outline some experiments that could reveal the putative correspondences between OS and OA.

As we have seen, OS hypothesises the existence of three operational levels in linguistic thought, which can be related to OMs of different complexity in the OA framework:

1) the level of the basic or elemental mental operations (EOMC) of linguistic thought, which could correspond to the simple OMs;

2) the level of mental categories, which are made up of EOMC. In some cases, we have hypothesised that we do not apply the EOMC to objects, but to spatial and temporal "maps", that is, our mental representations of space and time, respectively, so that we could also look for something that corresponds to these "maps" or to their activation. This level could correspond to the complex OMs;

3) the level of correlational network (correlata tied by particular mental categories, correlators). This level could correspond to the consequent set of complex and simple OMs (that is, the "very complex OMs" of Table 1).

Therefore, we can look for correspondences between OS and $\mathrm{OA}$ at these three operational levels. Let's consider them 
separately, taking the set of EOMC proposed by Benedetti and Ceccato's correlational model as a first starting point for the search of possible correspondences between OS and OA.

\section{1) Elemental Operations}

\section{a) Operation of Attentional Focalization (AF)}

To look for correspondences between the OMs and this operation, is obviously fundamental. Nevertheless, at this level we could encounter at least two kinds of difficulties. The first one is related to the fact that, when we pay attention, we pay attention to something. Obviously, in our study we must consider only very simple, physical situations. In human beings, the predominant sense is sight and we tend to use sight when we are in front of physical situations. The fact is that when we pay attention to the visual features of an object, that is, when we look at it, we perform a very complex perceptual activity, which very probably needs the integration of the activity of distinct nervous structures that process in a parallel way the information concerning shape, colour, movement etc $[111,112]$. Obviously, all this complex activity is reflected in the electrical activity recorded by the EEG. Therefore, it would be necessary to somehow separate as much as possible the operation of attentional focalization per se from this complex activity.

The second kind of difficulty is due to the fact that, as Cognitive Psychology shows, the operation of attentional focalization can be divided in turn into at least three elemental operations: a) engaging on a target b) disengaging from it c) and then shifting to a new target [67-69]. If we accept the hypothesis that there is a correspondence between simple OMs and EOMC, we have to expect that these three suboperations will have some correspondence in the structure of simple OMs. We also have to notice that the execution of these three sub-operations is surely influenced by some other factors. That is, the acts of paying attention to a certain object rather than to another, of disengaging from it, and of shifting to some new object rather than to another may be induced either by an explicit act of will of the subject, by some external sensory stimuli, or by some linguistic input. Therefore, given the aforesaid hypothesis, we might expect that these various factors will also be reflected in OMs' parameters/features.

In order to overcome these difficulties, a first approach would recommend comparing the bioelectrical activity of a subject (indexed by OMs) in a condition of complete rest with the one of a subject who is carrying out attentional tasks that are as simple as possible. These simple tasks should be accomplished in several different conditions, such as across different sensory modalities, so that it could be possible to identify the common features characterizing the pure act of attentional focalization.

A second kind of approach could be that of examining the OMs when subjects are presented with certain verbs, such as "to look" and "to listen". Indeed, according to OS, these verbs designate the operation of applying attention in a pure form to a sensory "channel" (the visual one or the acoustic one, respectively), which implies not paying attention to any specific object. The data of these experiments should be compared with the data achieved when subjects use the verbs "to see" and "to hear", which according to OS designate, on the contrary, the results achieved through applying attention to the relevant sensory channel.

\section{b) Operation of Representation ( $R$ )}

When representing the mental image of something physical, surely the sensory receptors are not working, but the nervous structures involved in its perception could be, at least partially, active: therefore, in this case there could be more or less the same problems as when the object is actually perceived. On the contrary, when we simply understand the meaning of a word without forming the corresponding mental image, these problems should be absent or less important. Therefore, experimental conditions should be devised that allow the formation of mental representations without the concurrent formation of the corresponding mental image: for example, subjects should be told that their task is only to understand the meanings of words without forming the corresponding mental image. This could also serve to better understand the difference between these two phases.

\section{c) Presence Keeping (PK)}

This operation is of fundamental importance. It is probably present in all mental categories, surely in correlators. Therefore, without it linguistic thought (as well as any other mental object or scene [1]) would not even exist. At first sight, it seems easier to identify the $\mathrm{OM}(\mathrm{s})$ corresponding to this operation than the $\mathrm{OM}(\mathrm{s})$ corresponding to attentional focalization and representation. Indeed, it could be enough to observe, by means of the aforesaid EEG techniques, what differences exist between two experimental conditions. In the first condition, a subject should be told to represent, separately, two objects (or an object and one of its features, i.e., colour, shape, etc.). In the second condition, the subject should be told to connect the two objects by means of the conjunction "and" (or to link the object and its feature by means of the correlation substantive-adjective). In fact, as we have seen in the second section, according to OS, both these correlations are produced by presence keeping. In such a kind of experiment, the only thing that seems to change is the very presence or absence of the operation of presence keeping. It would also be interesting to look for the differences (if any) between a situation in which the correlator is the conjunction "and" and a situation in which it is the "implicit correlator".

Although we are still dealing with the same operation (presence keeping), the situation gets more and more complex when the correlational network of linguistic thought is involved, that is, when one or more correlations become the correlata of other correlations. In such a case, it could be harder and more complicated to get bioelectrical evidence (indexed by $\mathrm{OM}$ ). Surely, we must start from situations where only one correlation is involved.

\section{d) Operation of Attentional Discarding (AD)}

This operation can be easily recognized when the conjunction "or" is used, as for example in the expression "glass or bottle". In this case, we believe that both objects are focused on by attention and kept present, but when our attention focuses on the glass, we must exclude, discard the bottle. According to OS, there is only one difference between 
the structure of the mental category referred to by the conjunction "or" and that referred to by the conjunction "and": the presence of the operation of $\mathrm{AD}$ in the former. The comparative analysis of the electrical activities (indexed by OMs) corresponding to pairs of expressions such as: "bottle and glass" vs. "bottle or glass" should therefore be the easiest way to reveal if and how this hypothetical operation is expressed in the EEG structure. It must be noticed, however, that also in this case the operation is always applied to something and that consequently we could encounter the difficulties mentioned at point a).

\section{e) Operation of Comparison (C)}

Our mind continuously makes comparisons. Every time we use words expressing some kind of judgment, whether concerning simple physical properties (like "high/low", "big/little", "long/short", "strong/weak", "heavy/light" etc.) or reflecting psychological or cultural qualities (like "good/bad", "normal/abnormal", "legal/not legal" etc.), we make comparisons. At this stage of experimentation, words expressing psychological and cultural judgments must be excluded, because they involve the assumption by the subject of some kind of attitude (such as an aesthetic one or an ethic one), that is, a very complex mental activity $[16,57]$. No doubt the words expressing judgments concerning physical properties involve a simpler kind of mental activity; nevertheless also with them we have to face a very complex situation because they involve either a spatial representation or some other kind of operation. Therefore, in order to carry out our experiments, it seems to us that it is better to start with the mental category "plural", whose structure we believe to be simpler. Obviously, the operation of comparison implies that the two things being compared are both focused on by attention, and that the first thing is kept present while we pass to the second one. For this reason, both the operations of attentional focalization and of presence keeping are involved when a comparison is made. Moreover, also the operation of comparison is always applied to something: therefore, we have to face the aforementioned difficulties.

\section{f) Memory Operations (MO)}

In the second section, we have said that, according to OS, memory operations are part of the structure of some mental categories. An example is given by the categories "the same" and "other/else". Let's briefly see the analyses Benedetti proposes for them [38]. There are a lot of objects of which many specimens exist, which are thus designated with the same word. For example, the word "dog" indicates each specimen of the class of "dogs". If, in a speech, after having found the word "dog" we find it once again, we remember that the word has already been used, so we have to know whether the latter word is referred to the aforementioned dog (let's call it $\operatorname{dog} A$ ) or not. The mental category the same indicates that we have to focus our attention on the $\operatorname{dog} A$ retrieved from memory, while the category other indicates that we have to discard the $\operatorname{dog} A$ retrieved from memory and represent a new specimen of the class of dogs, let's say $B$.

In the experiment, subjects should be showed first an item $a$ belonging to the class $A$, then an item $b$ belonging to the class $B$, then an item $a_{1}$ of the same class of $a$, so that they can say "another $a$ ".

\section{2) Mental Categories}

a) The simplest and most used mental category is the one referred to by the implicit correlator. Considering its importance and simplicity, it should be the first mental category to be taken into consideration when analysing the bioelectrical activity revealed by the aforesaid EEG techniques. Because we have hypothesised that the mental category "and" and the implicit correlator have a very similar structure (see 1c), it is logical to study these two categories together. The experiments have already been outlined at point $1 \mathrm{c}$.

b) "Numbers" and "plural" form a particular group of mental categories. As we said, we suppose that numbers are the result of an iterative repetition of the same basic mental operations. We think that "counting" consists of a series of operations, one following the other, of focalization of attention on each object of a group of objects which are considered equal (operation of comparison), maintaining mentally present the preceding objects each time we add a new one. If each successive repetition is named by a different name we obtain the single numbers ("one", "two", "three" etc.), otherwise we obtain the plural. This iterative repetition should be mirrored in the EEG structure.

c) Some mental categories have a structure that is partially the same or are made up of the same basic mental operations, but in a different, sometimes reversed, order. We think that it is worthwhile taking into consideration some of these mental categories when performing the experiments. Some examples are the following.

i. As we saw, OS hypothesises that the preposition "with" and the verb "to have" are based on the same core of operations (attention first focuses on an object $A$, then it also extends to another object $B$, because $B$ is in such a relationship with $A$ that attention is induced to focus $A$ and $B$ as a unity, together), except that the verb "to have", as all verbs, involves that we see the situation from the temporal point of view. The aforesaid analogy should be mirrored at the level of OMs.

ii. OS also proposes that the verbs "to have" and "to get" have the same structure, except that in the case of the verb "to have", the result is something static (that is, the relationship we have just described between two objects remains constant throughout time), while, in the case of the verb "to get", the result is something dynamic (the relationship, which is not present at the beginning, becomes present at a later moment). If this is correct, this should also be mirrored at the level of the OMs.

iii The mental categories "same" and "other" have a structure that is partly the same and partly different and opposite (see above).

iv. Of course, the mental categories "end" and "beginning" should have an opposite structure. Benedetti has proposed that the category end indicates that attention moves on an object $A$ in a linear way until it meets with something different (operation of comparison), $B$; then, it goes back and focus on the point 
of separation between $A$ and $B$ or the last part of $A$. As far as the mental category of beginning is concerned, attention moves on an object $A$ in a linear way, then, it goes back until it meets with something different (operation of comparison), $B$, and focus on the point of separation between $A$ and $B$ or the first part of $A[23]$.

v. Most probably, the structure of the mental category "without" is partly similar to that of the preposition "with". In fact, contrary to "with", without indicates that the second object of the relationship referred to by "with" is missing. Therefore, in the case of "without", we do not have the same relationship between two objects as the one referred to by "with", but something induces us to represent it anyway. What induces us to represent it may be the situation or a specific question (for example, when looking at a window without panes, we are led to say "window without panes", because we are used to seeing and representing windows with panes; or we can answer that we are "without money", if asked to say "how much money" we have). Consequently, the brain OMs related to these two prepositions should be partly the same and partly different.

vi. As we have said, the preposition "with" and the meaning of the genitive case should have a partly similar and partly different structure (see above). We expect that these relations will be reflected in the EEG structure.

\section{3) Correlational Network}

Al. and An. Fingelkurts maintain that the mean durations of OMs vary from $80-100 \mathrm{~ms}$ to $30 \mathrm{~s}$ [35]. Such durations are perfectly compatible with the durations of "correlational networks" hypothesised by OS. A correlational network represents a complete linguistic thought, that is, a sentence delimited by two full stops (according to OS, a full stop indicates the end of a correlational network). OMs, or some of them, or a set of them could then correspond to these correla-
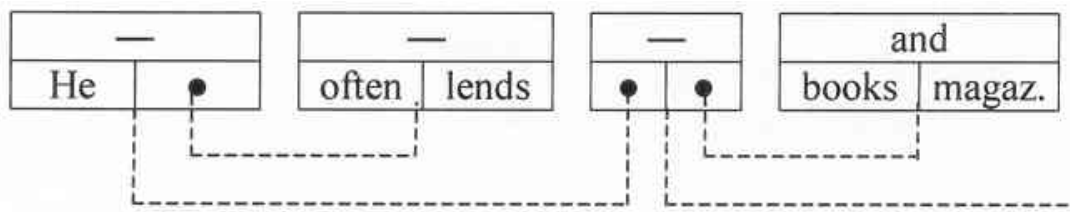

tional networks of different complexity. Indeed, the correlational theory of linguistic thought is based on the main idea that linguistic thought is composed of elements (mainly representations of physical or psychical things) that are somehow connected to each other. Since these representations are probably generated in different areas of the brain, OMs (or some of them) may be the result of operational synchrony [26-28, 34-36] that mirrors the activity necessary to bind these representations together. To verify this idea, experiments must be devised that highlight the differences in OMs between a situation in which subjects represent very simple, isolated objects, and a situation in which subjects generate a linguistic thought by means of these different objects. For example, subjects can be requested first to separately imagine the meanings of "glass", "bottle" and "cork", and then to form the thought "glass and bottle with cork".

In connection to this it will be interesting to look at the following hypothesis. There are sentences in which one word occurs repeatedly. In a brain model of language [6] postulating that each word is represented in one spatio-temporal brain pattern (OM in our interpretation), additional assumptions must be made in order to allow for a representation of sentences with multiple appearances of the same word. If there is only one OM representing an individual word, different states of activity of this OM may be assumed to correspond to the number of occurrences of this word in a particular sentence. Another important issue is to try to show the existence in EEG structure of some pattern(s) corresponding to the implicit correlator, which is the most recurrent element in correlational networks (which represents sentences). Indeed, in a correlational network, if the correlator is neither a conjunction, nor a preposition, nor a grammatical case, it is the implicit correlator. For example, in the following sentence:

He often lends books and magazines to French boys which, from a certain point of view, can be considered a typical one (there is a subject, a verb, an adverb, a direct object, an indirect object, a conjunction and a preposition), there are four implicit correlators, as we can see below.
One can also verify whether, given certain sentences, there is a correspondence between the complexity of the relevant correlational networks and the complexity/duration of the OMs observed when these sentences are thought about. One can also devise some sentences whose correlational networks have or share some structural relationships (such as, common parts, inverted parts, etc.), and then verify if similar structural relationships can be found at the OMs level.

\section{CONCLUSIONS}

Modern neuroscience can no longer ignore the mind phenomenon and is progressively starting to address the mindbrain problem seriously. This paper offers one way of dealing with this problem. We propose a plausible framework, which is based on the notion of operation and unifies within the same conceptual tissue mind Operational Semantics [20, 23, 38] and brain Operational Architectonics [26-28, 34-36]. We also provide a set of first experiments aiming to verify the putative correspondence we put forward between the OMs and what we consider to be the basic structure of a linguistic thought. As such, they can be further modified and developed.

Summarizing: The first step would be that of identifying the right level of correspondence between the (simple or complex) OMs discovered by OA and the EOMC, mental categories and correlational networks hypothesized by OS. Even if some first indications seem to show that some OMs are equivalent to basic mental operations (for instance, "keeping in mind" = "presence keeping"; "retrieval" = "representation"), additional tests are needed to support the hypothesis: they will show whether the same OMs configura- 
tions (be it, for example, that of "keeping in mind") are present in different conditions where OS supposes they should be present (for example, when one uses the word "and" or the correlation adjective-noun) or not.

Ultimately, this research can be seen as a part of the larger research project concerning the neural correlates and/or neural constituents of phenomenal consciousness, where the term "phenomenal" refers to the undeniable facts (phenomena) of immediate subjective experience (including higher-order reflective forms) that occur to us (for a complete discussion, see Revonsuo [1, 30, 36].

\section{REFERENCES}

[1] Revonsuo A. Inner presence. Consciousness as a biological phenomenon. Cambridge: MIT Press 2006

[2] Tranel D, Damasio AR. The neurobiology of knowledge retrieval. Behav Brain Sci 1999; 22: 303.

[3] Posner MI, Di Girolamo GJ. Flexible neural circuitry in word processing. Behav Brain Sci 1999; 22: 299-300.

[4] Salmelin R, Helenius P, Kuukka K. Only time can tell - words in context. Behav Brain Sci 1999; 22: 300.

[5] Skrandies W. Early effects of semantic meaning on electrical brain activity. Behav Brain Sci 1999; 22: 301-2.

[6] Pulvermüller F. Words in the brain's language. Behav Brain Sci 1999; 22: 253-336.

[7] Pulvermüller F. The neuroscience of language. On brain circuits of words and serial order. Cambridge: Cambridge University Press 2002.

[8] Shore DI, Spence C, Klein RM. Visual prior entry. Psychol Sci 2001; 12: 205-12.

[9] Shore DI, Spence C. Prior entry. In: Itti L, Rees G, Tsotsos J, Eds. Neurobiology of Attention. North Holland: Elsevier 2004.

[10] Wundt W. Grundzüge der physiologischen Psychologie. Leipzig: Engelmann 1902.

[11] Vicario GB. Il tempo. Saggio di psicologia sperimentale. Bologna: Il Mulino 2005.

[12] Varela FJ, Toro A, John ER, Schwartz EL. Perceptual framing and cortical alpha rhythm. Neuropsychologia 1981; 19: 675-86.

[13] Morris D. The sense of space. New York: Suny 2004.

[14] Haikonen PO. The cognitive approach to conscious machines. Exeter UK: Imprint Academic 2003.

[15] Ceccato S. L'osservazione nell'uomo e nella macchina. Civiltà delle macchine 1962; pp.18-30.

[16] Ceccato S, Ed. Corso di linguistica operativa. Milano: Longanesi 1969.

[17] Ceccato S. La mente vista da un cibernetico. Torino: Eri 1972

[18] Ceccato S. Intervento di Silvio Ceccato. In: Linguiti GL, Ed. Macchine e Pensiero. Da Wiener Alla Terza Cibernetica. Milano: Feltrinelli 1980.

[19] Ceccato S, Zonta B. Linguaggio consapevolezza pensiero. Milano: Feltrinelli 1980.

[20] Marchetti G. A presentation of attentional semantics. Cogn Process 2006; 7: 163-94

[21] Benedetti G. A presentation of operational methodology. 2005. Available from: http://www.mind-consciousness-language.com . [Cited 23 Oct 2008].

[22] Benedetti G. Basic mental operations which make up mental categories. 2005. Available from: http://www.mind-consciousnesslanguage.com . [Cited 23 Oct 2008].

[23] Benedetti G. Operational noology as a new methodology for the study of thought and language: theoretical aspects and possible practical applications. Cogn Process 2006; 7: 217-43.

[24] Marchetti G. The mechanics of the mind. Roma: Espansione 1993.

[25] Marchetti G. Observation levels and units of time: a critical analysis of the main assumption of the theory of the artificial. AI Soc 2000; 14: 331-47.

[26] Fingelkurts AnA, Fingelkurts AlA. Operational architectonics of the human brain biopotential field: towards solving the mind-brain problem. Brain Mind 2001; 2: 261-96.
[27] Fingelkurts AnA, Fingelkurts AlA. Mapping of brain operational architectonics. In: Chen FJ, Ed. Focus on brain mapping research. New York: Nova Science Publishers Inc 2005; pp. 59-98.

[28] Fingelkurts AnA, Fingelkurts AlA. Operational architectonics of perception and cognition: a principle of self-organized metastable brain states. VI Parmenides Workshop, Institute of Medical Psychology. Elba/Italy 2003.

[29] Stubenberg L. Consciousness and qualia. Amsterdam: John Benjamins 1998 .

[30] Fingelkurts AnA, Fingelkurts AlA, Neves CFH. Brain and mind operational architectonics and man-made "machine" consciousness. Cogn Process 2009; 10: 105-11.

[31] Kaplan AY, Brodsky BE, Darkhovsky BS, Shishkin SL, Fingelkurts AlA, Fingelkurts AnA. Change-point mapping: a new technique for EEG brain imaging. Proceedings of the First International Conference on Functional Mapping of the Human Brain Hum Brain Mapp 1995; vol. 1: p.97.

[32] Kaplan AY.. Nonstationary EEG: methodological and experimental analysis. Usp Physiol Nayk (Success Physiol Sci) 1998; 29: 35-55. (in Russian).

[33] Kaplan AY. The problem of segmental description of human electroencephalogram. Hum Physiol 1999; 25: 107-14.

[34] Fingelkurts AnA, Fingelkurts AlA. Making complexity simpler: multivariability and metastability in the brain. Int J Neurosci 2004; 114: 843-62.

[35] Fingelkurts AnA, Fingelkurts AlA. Timing in cognition and EEG brain dynamics: discreteness versus continuity. Cogn Process 2006; 7: 135-62.

[36] Fingelkurts AnA, Fingelkurts AlA. Brain-mind operational Architectonics imaging: technical and methodological aspects. Open Neuroimag J 2008; 2: 73-93.

[37] Fingelkurts AnA, Fingelkurts AlA, Neves CFH. Functional isomorphism between operational architectonics of brain functioning and subjective phenomenology. Proceedings of the International Conference - Coordination Dynamics: Coordination: Neural, Behavioral and Social Dynamics. Boca Raton, Florida 2007.

[38] Benedetti G. A semantics "outside language": operational semantics. A new semantic theory, based on the nature and structure of thought. 2008. Available from: http://www.mind-consciousnesslanguage.com . [Cited 23 Oct 2008].

[39] Wierzbicka A. Semantic primitives. Frankfurt: Athenäum 1972

[40] Wierzbicka A. Semantic primitives and lexical universals. Quaderni di Semantica 1989; X(1): 103-21.

[41] Wierzbicka A. Semantic primitives: the expanding set. Quad di Semantica 1989; X(2): 309-32.

[42] Wierzbicka A. The search for universal semantic primitives. In: Pütz M, Ed. Thirty Years of Linguistic Evolution. Amsterdam/Philadelphia: John Benjamins 1992; pp. 215-42.

[43] Goddard C. Conceptual primes in early language development. In: Putz M, Niemeier S, Dirven R, Eds. Applied cognitive linguistics I: theory and language Acquistition. Berlin: Mouton de Gruyter 2001; pp.193-227.

[44] Goddard C. The search for the shared semantic core of all languages. In: Goddard C, Wierzbicka A, Eds. Meaning and Universal Grammar. Theory and Empirical Findings. Amsterdam/Philadelphia: John Benjamins 2002; vol. 1: pp.5-40.

[45] Goddard C, Wierzbicka A, Eds. Semantic and lexical universals Theory and empirical findings. Amsterdam/Philadelphia: John Benjamins 1994

[46] Goddard C, Wierzbicka A, Eds. Meaning and Universal Grammar. Theory and Empirical Findings. Amsterdam/Philadelphia: John Benjamins 2002; vol. 2.

[47] Marchetti G. A criticism of Leonard Talmy's cognitive semantics. 2006. Available from: http://www.mind-consciousnesslanguage.com . [Cited 23 Oct 2008].

[48] Vaccarino G. Scienza e semantica costruttivista. Milano: Clup 1988.

[49] Oliva C. La passeggiata. In: Ceccato S, Oliva C, Eds. Il linguista inverosimile. Una passeggiata fra esperienze ed esperimenti della parola. Milano: Mursia 1988; pp. 39-133.

[50] De Vincenzi M, Di Matteo R. Come il cervello comprende il linguaggio. Roma-Bari: Laterza 2004. 
[51] Friederici AD. Towards a neural basis of auditory sentence processing. Trends Cogn Sci 2002; 6: 78-84.

[52] Graffi G, Scalise S. Le lingue e il linguaggio. Bologna: il Mulino 2002.

[53] Robins RH. A short history of linguistics. London: Addison Wesley Longman 1997.

[54] Benedetti G. La categoria di "spazio" and Tavole sinottiche delle analisi di categorie mentali tratte dalle opere di S. Ceccato. In: Accame F, von Glasersfeld E, Somenzi V, et al., Eds. Studi in Memoria di Silvio Ceccato. Roma: Società Stampa Sportiva 1999; pp. 167-235.

[55] Benedetti G. Semantica operativa. 2004. Available from: http://www.mind-consciousness-language.com . [Cited 23 Oct 2008].

[56] Benedetti G. On Giorgio Marchetti's commentary on my book "Semantica Operativa" [Operational Semantics], 2004; vol. I. Available from: http://www.mind-consciousness-language.com . [Cited 23 Oct 2008].

[57] Marchetti G. La macchina estetica. Il percorso operativo nella costruzione dell'atteggiamento estetico. Milano: Franco Angeli 1997.

[58] Marchetti G. A Theory of Consciousness. 2001. Available from: http://www.mind-consciousness-language.com . [Cited 23 Oct 2008].

[59] Marchetti G. Foundations of Attentional Semantics. 2003. Available from: http://www.mind-consciousness-language.com . [Cited 23 Oct 2008].

[60] Marchetti G. The importance of non-attentional operations for Attentional Semantics. 2005. Available from: http://www.mindconsciousness-language.com . [Cited 23 Oct 2008].

[61] Barsalou LW. Perceptual symbol systems. Behav Brain Sci 1999; 22: 577-660.

[62] Lakoff G. Women, fire, and dangerous things. Chicago: The University of Chicago Press 1987.

[63] Rosch E. Natural categories. Cogn Psychol 1973; 4: 328-50.

[64] Rosch E. Principles of categorization. In: Rosch E, Lloyd B, Eds. Cognition and categorization. Hillsdale: Lawrence Erlbaum Ass 1978.

[65] James W. The principles of psychology. New York: Holt 1889 (Reprint: Cambridge: Harvard University Press, 1983).

[66] Ribot T. Psychologie de l'attention. Paris: Alcan 1889.

[67] Posner MI. Orienting of attention. Q J Exp Psychol 1980; 32: 3-25.

[68] Posner MI. Attention in cognitive neuroscience: an overview. In: Gazzaniga M, Ed. The cognitive neurosciences. Cambridge: MIT Press 1994.

[69] Posner MI, Cohen Y. Components of performance. In: Bouma H, Bowhuis D, Eds. Attention and Performance. Hillsdale: Erlbaum 1984.

[70] Jonides J. Further toward a model of the mind's eye's movement. Bull Psychon Soc 1983; 21: 247-50.

[71] La Berge D. The spatial extent of attention to letters and words. J Exp Psychol Hum Percept Perform 1983; 9: 371-79.

[72] La Berge D. Attentional processing. The brain's art of mindfulness. Cambridge: Harvard University Press 1995.

[73] Pashler HE. The psychology of attention. Cambridge: MIT Press 1998.

[74] Braga-Illa F. Esperienza e rappresentazione. Bologna: Pitagora 1985.

[75] Braga-Illa F, Ed. Livelli di rappresentazione. Urbino: QuattroVenti 1996.

[76] Braga-Illa F, Ed. A proposito di rappresentazioni. Alla ricerca del senso perduto. Bologna: Pendragon 2006.

[77] Denis M. Image et cognition. Paris: Presses Universitaires de France 1989.

[78] Baddeley AD. The episodic buffer: a new component of working memory? Trends Cogn Sci 2000; 4: 417-23.

[79] Baddeley AD, Hitch GJ. Working memory. In: Bower GA, Ed. Recent advances in learning and motivation. New York: Academic Press 1974; vol. 8: pp. 47-90.

[80] Cowan N. The magical number 4 in short-term memory: a reconsideration of mental storage capacity. Behav Brain Sci 2001; 24: 87-185.
[81] Cowan N. Working memory capacity. New York: Psychology Press 2005.

[82] Miller GA. The magical number seven, plus or minus two: some limits on our capacity for processing information. Psychol Rev 1956; $63: 81-97$.

[83] Oberauer K. Access to information in working memory: exploring the focus of attention. J Exp Psychol Learn Mem Cogn 2002; 28 : 411-21.

[84] Oberauer K, Süß H.-M, Schulze R, Wilhelm O, Wittmann WW. Working memory capacity - facets of a cognitive ability construct. Pers Individ Dif 2000; 29: 1017-45.

[85] Carstensen K-U. Focused spatial attention and spatial semantics: The case of 'to follow'. Proceedings of the TSM'95 1995; pp. 1527.

[86] Carstensen K-U. Location and distance in language: An attentionbased approach. Proceedings of the 3rd Annual Language \& Space Workshop 'Resolution and Granularity in Language and Space'.Bielefeld: ZIF, University 2002.

[87] Carstensen K-U. Spatio-temporal ontologies and attention. Spat Cogn Comput 2007; 7 (1): 3-12.

[88] Marchetti G. Studies on time: a proposal on how to get out of circularity. Cogn Process 2009; 10: 7-40.

[89] Amietta PL, Magnani S. Dal gesto al pensiero. Milano: Franco Angeli 1998.

[90] Vaccarino G. Analisi dei significati. Roma: Armando Armando 1981.

[91] Revonsuo A. Can functional brain imaging discover consciousness in the brain? J Consc Stud 2001; 8: 3-23.

[92] Tononi G, Edelman GM. Consciousness and complexity. Science 1998; 282: 1846-51.

[93] Varela FJ. Resonant cell assemblies: a new approach to cognitive functions and neuronal synchrony. Biol Res 1995; 28: 81-95.

[94] Baars BJ. A cognitive theory of consciousness. New York: Cambridge University Press 1988.

[95] Crick F, Koch C. A framework for consciousness. Nat Neurosci 2003; 6: 119-26.

[96] Chalmers DJ. Consciousness and its place in nature. In: Chalmers D, Ed. Philosophy of Mind: classical and Contemporary readings. New York: Oxford University Press 2002; 247-72.

[97] Searle JR. The rediscovery of mind. Cambridge: MIT Press 1992.

[98] Hebb DO. The organization of behavior. New York: Wiley 1949.

[99] von der Malsburg C. The what and why of binding: the modeler's perspective". Neuron 1999; 24: pp. 95-104.

[100] Pelliomisz A, Llinas R. Tensor network theory of the metaorganization of functional geometries in the central nervous system. Neuroscience $1985 ; 16: 245-73$.

[101] Nunez PL. Toward a quantitative description of large-scale neocortical dynamic function and EEG. Behav Brain Sci 2000; 23: 37198 .

[102] Makarenko V, Llinas R. Experimentally determined chaotic phase synchronization in a neuronal system. Proc Natl Acad Sci USA 1998; 95: 15747-52.

[103] Kirillov AB, Makarenko VI. Metastability and phase transition in neural networks: statistical approach. In: Holden AV, Kryukov VI, Eds. Neurocomputers and Attention. Manchester: Manchester University Press 1991; vol. 2. pp. 825-922.

[104] Kaplan AYA, Fingelkurts AnA, Fingelkurts AlA, Borisov SV, Darkhovsky BS. Nonstationary nature of the brain activity as revealed by EEG/MEG: Methodological, practical and conceptual challenges. Signal Process 2005; 85: 2190-212.

[105] Kelso JAS. Dynamic patterns: the self-organization of brain and behavior. Cambridge: MIT Press 1995.

[106] Bressler SL, Kelso JAS. Cortical coordination dynamics and cognition. Trends Cogn Sci 2001; 5: 26-36.

[107] Shannon CE. A mathematical theory of communication. Bell Syst Technol J 1948; 27: 379-423, 623-56.

[108] Aquinas St. Thomas: treatise on man. In: Sullivan DJ (rev.) Summa Theologica: Translated by Fathers of the English Dominican Province. vol. 19. Chicago: Great Books Series, Encyclopedia Britannica 1952; vol. 1272; pp. 378-487.

[109] Oakley TH. Elements of attention: a new approach to meaning construction in the human sciences. 2004. Partly available from: 
http://www.mind-consciousness-language.com/articles oakley1.htm [Cited 23 Oct 2008]

[110] Tomasello M. The cultural origins of human cognition. Cambridge: Harvard University Press 1999.
[111] Damasio AR. Time-locked multiregional retroactivation: a systems-level proposal for the neural substrates of recall and recognition. Cognition 1989; 33: 25-62.

[112] Treisman A. The binding problem. Curr Opin Neurobiol 1996; 6: 171-78.

(C) Benedetti et al.; Licensee Bentham Open.

This is an open access article licensed under the terms of the Creative Commons Attribution Non-Commercial License (http://creativecommons.org/licenses/by-nc/3.0/) which permits unrestricted, non-commercial use, distribution and reproduction in any medium, provided the work is properly cited. 